\title{
Evolution of ideas towards the implementation of nanoparticles as flotation reagents
}

\author{
Krzysztof Jan Legawiec, Izabela Polowczyk
}

Department of Process Engineering and Technology of Polymer and Carbon Materials, Wroclaw University of Science and Technology, Norwida 4/6 St., Wroclaw, Lower Silesia 50-373, Poland

Corresponding author: krzysztof.legawiec@pwr.edu.pl (K. Legawiec)

\begin{abstract}
The paper discusses an idea of nanoparticles application to the flotation process. Due to the growing awareness of the environmental impact of industry and legal restrictions, the directions of research on new chemicals used in mineral processing, as well as in the other branches of industry are changing. The flotation reagents of the future should be, or are expected to be, readily biodegradable, but also their products should be harmless to the environment. A review of the works presented here presents an overview of the state-of-the-art application of nanostructures from early reported polystyrene nanoparticles to the most promising cellulose nanostructures which can be successfully adapted to the desired amphiphilicity parameters through simple functionalization. Limitations on the use of such nano-sized entities related to control aggregation in the flotation process and the ability to adsorb at interphase boundaries are also presented. Overall, nanoparticles can become universal flotation collectors and also an alternative to conventionally used hydrocarbon-based reagents.
\end{abstract}

Keywords: nanoparticles, nanocelluloses, polystyrene, nano-collectors, green flotation chemicals

\section{Introduction}

Froth flotation is a separation process used in many various branches of industry. It has found its widest application in the mineral processing sector (Fuerstenau et al., 2007). The most important phenomenon to be discussed is that separation by flotation is the formation of a gas bubble-solid particle aggregate. On the one hand, what is required to establish such an aggregate is to obtain a critical size of solid particles. On the other, the wettability of the mineral particles surface must be appropriate for the process to be selective, i.e. to separate the desired components of the ore from the gangue. Modification of the wettability of particles is achieved through the use of various flotation agents - chemical reagents which modify the physicochemical properties of the mineral surface, making them sufficiently hydrophobic. These days, the main problem is that synthetic substances, which are derivatives of hydrocarbons mainly obtained from crude oil, are used as flotation reagents. It makes their biodegradation difficult, and their resources limited.

It is believed that in the field of flotation chemistry, the plateau of innovation has already been achieved (Nagaraj and Farinato, 2016). This is probably due to the fact that the schemes used for several decades to target process selectivity are well adapted for the industry. Widely used both synthetic molecules and natural oils are characterised by good efficiency and low unit cost. This makes them suitable for use; however, the growing pressure to balance the industry and reduce water consumption has led to attempts to take a new insight into the development of modern flotation chemicals for over ten years (Kyzas and Matis, 2019). Unfortunately, progressive ideas proposed by the world of science do not go hand in hand with industrial applications. To implement a technology developed on a laboratory-scale in an industrial application expensive and long-term research is necessary. The implementation of new flotation reagents is also hardly facilitated by the fact that the description of the physicochemistry of the flotation process has not yet been fully systematised and understood. 


\section{General characteristics of nanomaterials used in the flotation process}

Application of nanomaterials as flotation collectors is a relatively new approach according to data found in the literature. The first reported data was published by Yang et al. in 2011, and gave rise to research on an entirely new group of flotation reagents. This novel class of flotation reagents can be generally classified according to the characteristics of their material, which can be called "the core", and to which functional groups are attached as a result of chemical reactions. The aim of covering the surface of nanostructure with functional groups is to give the nanoparticles their desired properties. Similarly, the new class of collectors must possess the same specifications as currently used molecular collectors. Examples of the most popular existing flotation collectors with functional groups that only interact with particles with specific surface chemistry used for the separation of metal sulphides, are xanthogenate (Ackerman et al., 1987) or mixtures of different surface-affinity collectors, e.g. xanthogenate and phosphate (Dhar et al., 2019).

It is well known that an essential property of a flotation collector is the ability to adsorb selectively on the surface of mineral particles which need to be collected in an ore concentrate instead of on the gangue. Collector adsorption allows desired mineral particles to become more hydrophobic and easily attach to the air bubble. Abarca et al. (2018) suggested three features of an excellent nanoparticle collector related to its surface chemistry, which are as follows:

(1) the character of nanoparticle surface needs to be sufficiently hydrophobic to attach to air bubbles;

(2) the nanoparticles must not be aggregated under the flotation process;

(3) the selectivity should be satisfactory - the nanoparticles' adsorption must be directed towards the separated mineral, and thus deposition on a gangue should not occur.

Due to the importance of the functionalisation of nanostructures using cationic or anionic groups, and considering the nature of the core, it is quite challenging to meet all requirements. The nanoparticles' charge and hydrophilic nature of the core may lead to aggregation which consequently results in colloid sedimentation.

The above attributes can be achieved by modifying the surface of the cores. The functional nanostructures presented in the literature have cores that can be categorised into the following subgroups (Fig. 1):

- polystyrene nanoparticles,

- cellulose nanocrystals/nanofibers,

- inorganic nanoparticles.

Two of them, based on styrene and cellulose, are distinguished by their ability to easily modify surface physicochemistry. Inorganic nanoparticles are usually not chemically functionalised due to their structural nature. Although the functionalisation of inorganic nanostructures is a well-established process (Sperling and Parak, 2010), it has not been applied in the context of flotation collector development. Their use is mainly to stabilise the froth properly or to control bubble coalescence. In the next paragraph, all the listed groups will be discussed extensively, starting from the synthesis or preparation stage, to flotation studies involving metal ores. Their particular role in different stages of the flotation process is also presented.

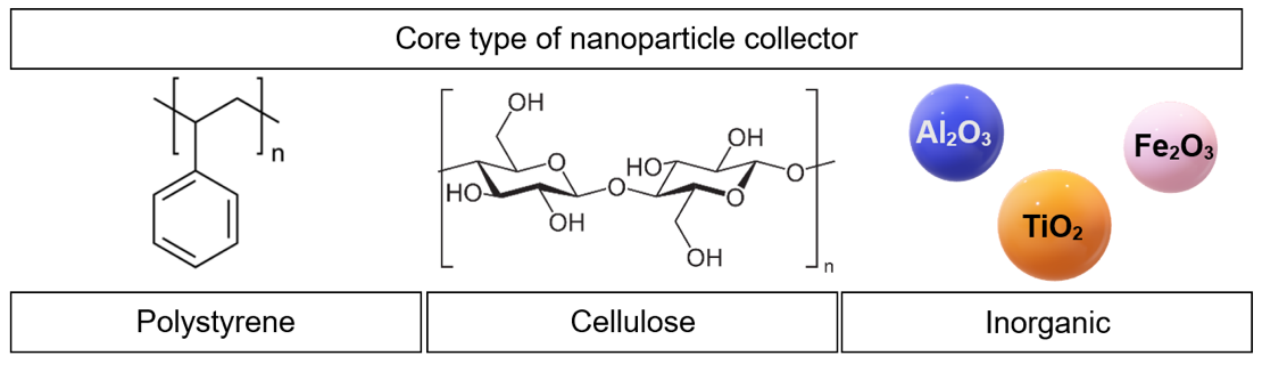

Fig. 1. Different types of cores used to make flotation reagents

\subsection{Polystyrene nanoparticles as collectors}

The first report on the potential use of polystyrene nanoparticles as a flotation collector was published by Yang et al. in 2011. The main idea of the proposed technology was to create hydrophobic nano- 
entities larger than typical flotation collectors, i.e. approx. 46-120 nm compared to $\sim 1 \mathrm{~nm}$, which can adsorb on the hydrophilic glass bead surface and induce the flotation process. The polystyrene fabrication process based on batch emulsion polymerisation resulted in two nanostructures stabilised by cationic moieties attached to its surface: amidine - emulsifier-free method (Goodwin et al., 1979) and quaternary ammonium - monomer-starved method (Sajjadi, 2006). The water wetting contact angle of the obtained polystyrene nanoparticles, determined by sessile drop method, was 91 and 85 degrees respectively. The Authors concluded from flotation experiments that for hydrophilic spherical glass beads the process is sufficiently effective if the surface coverage by nanoparticles is less than $10 \%$, and that smaller sizes and greater hydrophobicity of nanoparticle flotation collector can increase the efficiency of separation.

Further research on polystyrene nanoparticles concerned the influence of hydrophobicity (Yang et al., 2011), diameter (Yang et al., 2012) and softness of nanoparticles on the recovery of glass beads. It was found that flotation recovery was more significant if the hydrophobicity of the nanoparticles was bigger (Yang and Pelton, 2011). The ability to modify surface wettability has been confirmed by a test of both advancing and receding wetting contact angle measurements for different degree of glass beads surface coverage and for a thin polymeric film immobilised on the glass surface. The most important result of this work was to determine the minimum value of wetting contact angle for water, necessary to create a three-phase contact achieved after successful bubble attachment to the solid-liquid interface (Kosior et al., 2018) (Fig. 2B). The highest flotation recovery, assumed here as a measure of efficiency, was achieved for the value of the water wetting contact angle between $51-85^{\circ}$. The measurements were taken on a glass slide made of quartz with the same chemical composition as the hydrophilic glass beads used in the flotation experiment. The surfaces were coated with the film, providing the same surface character as that of nanoparticles that were employed for separation performance. These results refer to a surface almost completely saturated with this collector. If the saturation was insufficient, the surface was too hydrophilic, and there was no three-phase contact. In the case of glass slides covered with nanoparticles and then dried, flotation was found to be most effective at the contact angle of 30-40 . Taking into account the diameter of the nano-sized polystyrene collector in the range 46-2227 nm, the flotation efficiency increases with a decreasing nanoparticle diameter (Yang et al., 2012). This relationship is mainly explained by the fact that smaller particles can diffuse more rapidly to the interfacial boundary. It was correlated with the statement that if the concentration is too low to cover the entire surface of the glass, a certain mass of nanoparticles with a smaller diameter covers a larger area of the solid. These nanoparticles have a larger specific surface area and therefore increase the hydrophobicity more effectively. Comparing it to conventionally used flotation collectors, one can say that size limits the diffusion rate and thus determines the kinetics of adsorption on the surface of glass spheres. The smaller molecules/nanoparticles are, the faster the diffusion and adsorption occur.

The research discussed above was a milestone in the application of nanoparticles as flotation collectors. However, it focused on the study of the phenomenon of creating three-phase aggregates, where flotation recovery was considered as a measure of efficiency. It was realised by way of a study of the flotation system with a mineral model conception-based solid. The use of glass balls with the same surface physicochemistry did not allow to determine how selectively a particular nano-collector works. It is known, though, that the most critical parameter that determines the efficiency of the flotation process is the yield of the component that one wants to separate from the gangue rock.

An original technological solution was therefore to design and use appropriately functionalised nanoparticles as collectors in a pentlandite flotation. Yang et al. (2013) proposed the incorporation of amidine, vinyl imidazole and quarternary ammonium groups into polystyrene nanoparticles. Flotation of ultramafic nickel ore was performed in the Denver flotation cell. The authors chose imidazole substituents due to their affinity for complexation and protonation of $\mathrm{Ni}^{2+}$ cation, which was reported earlier (Lippert et al., 1985), and also as a chelating agent for sulphides, such as chalcopyrite, chalcocite, covellite, bornite and pyrite (Ackerman et al., 1999). The results of flotation experiments have shown that imidazole-functionalised styrene nanoparticles can be such of equal or even better effectiveness compared to potassium amyl xanthate (PAX), which is widely used in the mineral industry to separate pentlandite ores. Despite this better performance, the collector consumption was six times greater than 
PAX (13 mgg-1 versus $2.5 \mathrm{mgg}^{-1}$ for PAX). The authors suggested an application of such nano-collectors may lie only in complex systems where conventional chemicals do not work at a satisfactory level.

Raw polystyrene nanoparticles were useful in the separation of coal from high ash coal fines (An et al., 2015). In this case, it was possible to separate coal from ashes successfully, but the consumption of nanoparticles was significant (of about $2.5 \mathrm{mgg}^{-1}$ ). There was also an observed weak colloidal stability and a low ability for selective adsorption.

An et al. (2019) proposed a method of synthesis and application of tetrahydrofurfuryl-functionalized polystyrene nanoparticle in the flotation of low-rank coal. In comparison with commonly used oil collectors, a collector based on functionalised polystyrene has increased the hydrophobicity of coal surface. It was also found that the roughness of the surface increased in nanoscale. This has also been confirmed by SEM microphotographs it. In this case, the collector-mineral selective adsorption mechanism was explained based on specific interactions of tetrahydrofurfuryl groups with functional groups containing an oxygen atom (especially hydroxyl one) located on the surface of low-rank coal.

Regarding the stability of colloids, in general, the most important factors are ionic strength and $\mathrm{pH}$. It is known that these parameters are easily controlled in model systems, and more challenging to control in real systems, consisting of ores of different chemical composition. During the flotation process under conditions determined by the presence of raw material (flotation feed), nanoparticles tend to aggregate (Valle-Delgado et al., 2003). To solve this issue of control, there are two options to consider. One of them is related to the proper functionalisation of surface groups so that particles do not aggregate in a wide range of changes of the double electrical layer. Considering such a modification, it is important to remember that possible attached surface-functional group cannot limit nano-collector interactions with the mineral surface, and to keep in mind to decrease the hydrophobization potential of nanostructures (Abarca et al., 2015). The other way may be to control the system parameters mentioned above, such as $\mathrm{pH}$ and ionic strength. It should be noted that high ionic strength and high $\mathrm{pH}$ lead to nanoparticles' aggregation. However, it should also be considered that any change of one parameter of the system implies changes in its entire physicochemistry.

A

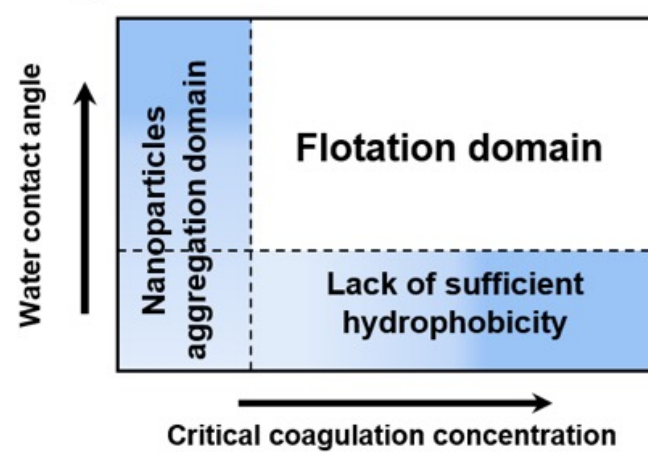

B

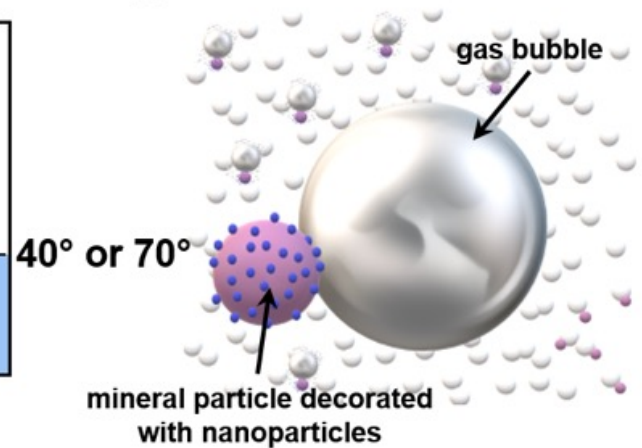

Fig. 2. Schematic representation of A - criteria for effective polystyrene nanoparticle collectors applied to the flotation process, B - three-phase flotation aggregate. Based on Robert H. Pelton conception (Abarca et al., 2015, 2018)

Because it would be very time consuming to develop a novel collector that would allow for an effective flotation process, Abarca et al. $(2015,2018)$ has proposed a strategy called high throughput screening. This strategy is aimed to eliminate the ideas for functional groups, which attached to polystyrene nanoparticle would not work as an effective flotation collector. The technology is based on the combinatorial synthesis of PEG-containing nanoparticles with modified surface properties. The number of tested surface groups is impressive. The authors created a library consisting of 78 nanostructures with different surface character by click chemistry modification of polystyrene-azide nanoparticles (Abarca et al., 2018). The evaluation of such massive amount of potential flotation reagents was possible by correlating the water contact angle with the critical coagulation concentration determined in the presence of sodium carbonate for obtained nanoparticles (Fig. 2A). The authors believe that the confrontation of these two parameters in the initial stage of designing new collectors 
enables an estimation of their usefulness. Nanoparticles showing hydrophobicity above $40^{\circ}$ were considered useful for further evaluation in the flotation tests. However, it is suspected that the flotation domain for nanoparticles should be above $70^{\circ}$ to ensure sufficient hydrophobicity.

\subsection{Functionalised nanocelluloses - novel and greener alternative for synthetic reagents}

Reagents based on cellulose are considered environmentally friendly due to their easy biodegradability and renewability. This non-branched biopolymer is the most common natural macromolecule of linear topology. Due to the big specific surface area, these molecules can be covered by groups that can interact with other entities (Suopäjarvi et al., 2015). Cationic and anionic groups can be distinguished among them. Relatively simple synthesis routes make nanocelluloses promising candidates for selective flotation reagents in order to facilitate a programmable functionalization. The literature on the mechanisms of nanostructures adsorption at the interphase boundaries is continually growing; however, the issues related to the application of nanocellulose in mineral processing require more extensive studies. The properties of nanocelluloses that affect adsorption at the interphase include charge, size and concentration, which can be controlled during the synthesis process. A more complex molecular architecture characterizes such nanostructures compared to conventionally used reagents, hence their influence on the flotation system is more difficult to describe.

The conclusions presented so far suggest that cellulose nanostructures with attached functional groups can be effective flotation collectors. Table 1. summarises the methods of nano-fibrillated celluloses (NFC) functionalisation and provides information about mineral particles used for flotation process performance. The first application of NFC to the flotation process was reported by Laitinen et al. in 2014. Separation of hematite and quartz in the presence of functionalised NFC was investigated. Two different types of NFC were produced through sequential periodate-chlorite oxidation (Sirviö et al., 2011; Liimatainen et al., 2012). The hydrophilic functionalisation was done by reaction with sodium chlorite. The diameter of the final product - dicarboxylic acid nanocellulose - was 3-8 nm, with a length from $100 \mathrm{~nm}$ to several micrometres. The amphiphilic structures were obtained by introduction of three butylamine isomers (tert-, iso- and $n$-butylamine) to the cellulose backbone. In this case, the nanofibres diameter was in the range of 3-6 nm, and the length ranged from 50 to $200 \mathrm{~nm}$. These dimensions were characterized by the analysis of images obtained through transmission electron microscopy.

Table 1. Data on flotation research using functionalised NFC

\begin{tabular}{|c|c|c|}
\hline Mineral type & Modification of celluloses & References \\
\hline \multirow{2}{*}{ Hematite } & Chlorite oxidation & \multirow[b]{2}{*}{ Laitinen et al., 2014} \\
\hline & Amination with tert-, iso-, $n$-butylamine & \\
\hline Quartz & Amination with $n$-butylamine & Hartmann et al., 2017 \\
\hline $\begin{array}{l}\text { Aluminum } \\
\text { oxide }\end{array}$ & $\begin{array}{c}\text { Amination with methyl-, ethyl-, n-propyl-, n-butyl-, n-hexyl- } \\
\text { amine }\end{array}$ & Laitininen et al., 2016 \\
\hline $\begin{array}{c}\text { Quartz } \\
\text { Rutile } \\
\text { Anatase }\end{array}$ & Catalytic solvolysis & $\begin{array}{l}\text { Krivoshapkina et al., } \\
2019\end{array}$ \\
\hline $\begin{array}{c}\text { Quartz } \\
\text { Hematite }\end{array}$ & Amination with butyl-and hexyl-amine & Hartmann et al., 2018 \\
\hline $\begin{array}{c}\text { Chalcopyrite } \\
\text { Sphalerite }\end{array}$ & Amination with butyl-amine & Lopéz et al., 2019 \\
\hline
\end{tabular}

An interesting comparison made in this study was to confront NFC with commercial flotation reagents typically used in such a system. Dicarboxylic acid NFC was a better depressant for hematite ( $\mathrm{pH} 6,0.1 \%$ dosage) than starch. The mechanism of this phenomenon was linked to hydrophilization of 
hematite surface due to the presence of anionic functional groups in the NFC structure. Moreover, for NFCs treated with butylamine isomers, it was observed that they could act as hematite collectors at $\mathrm{pH}$ above 8. This effect was most substantial for iso- and butyl-amine treated structures. Such results can also be explained by modifying the character of the surface, in this case, its hydrophobization, and changing surface potential. Good selectivity can be achieved in this system because, as was also observed, at pH 6 amine-functionalised structures acted as a collector for quartz at a similar level as the commonly used amine ether collector. Experiments conducted in the presence of different background electrolytes $\left(\mathrm{NaCl}\right.$ and $\left.\mathrm{MgSO}_{4}\right)$ resulted in finding optimum conditions for flotation with butylaminated NFCs at $\mathrm{pH}$ 9. For hexyl-aminated NFC, the best flotation recovery was achieved in the presence of magnesium sulphate as a background electrolyte at pH 7 (Hartmann et al., 2018).

One of the criteria that qualifies a substance as a good flotation collector is the ability to make the mineral surface sufficiently hydrophobic. Fig. 3 shows the wetting angle values published in several works.

For the system composed of aluminium oxide and quartz, successful flotation was performed at $\mathrm{pH}$ 7.5 with $0.05 \%$ dosage of $n$-pentyl- and $n$-hexyl- aminated NFC. In this case, nanocellulose works better as a collector for quartz than for aluminium oxide (Laitinen et al., 2016). For an attempt at a sustainable Panasqueria ore flotation, n-butyl-amine NFC was used (Lopéz et al., 2019). Application of functionalised nanocelluloses resulted in better flotation efficiency and selectivity in the separation of chalcopyrite occurring in this ore, than for originally used thiol collector. Moreover, the recovery of undesirable ore components such as arsenopyrite and sphalerite was reduced up to the level of lesser than $10 \%$.

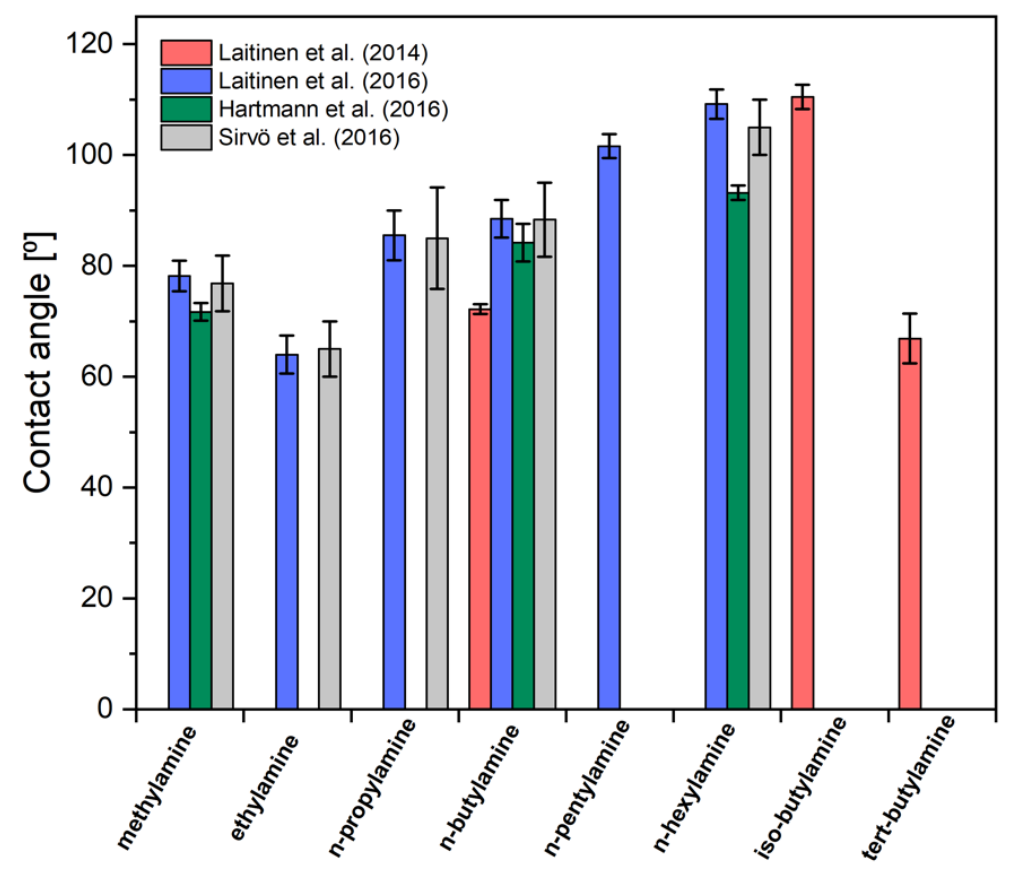

Fig. 3. Comparison of wetting contact angle values for NFC with introduced amine derivatives (sessile drop technique)

During the investigation of the surface modification ability of alkyl-aminated NFC, it was also observed that longer chain induced hydrophobicity of solid on which it was adsorbed. Also, the efficiency of quartz flotation is directly relevant to the hydrophobicity of generated nanostructures. Based on wettability studies for pellets coated with alkyl-aminated NFC, it was believed that surface free energy is lowering with increasing alkyl chain length (Hartmann et al., 2016), what could be attributed to real systems where the particles are naturally rough. Hartmann's subsequent study conducted using reverse gas chromatography demonstrated that each NFC modified by reductive amination reduce sufficiently free surface energy, and no correlation to the length of the alkyl chain was found (Hartmann et al., 2017). The study of interactions between quartz particles and gas bubbles in the 
presence of different NFC led to the conclusion that only hexyl-aminated NFC can sufficiently modify quartz surface, leading to high flotation recoveries. The significant forming of a flotation aggregate is related to the total physical adsorption phenomena in a flotation system that consists of functionalised nano-cellulose, mineral particle and gas bubble, which interact electrostatically with each other (Hartmann et al., 2018).

In the studies presented above, the size of the cellulose fibres was reduced from micrometric to nanometric by high-pressure homogenisation. Another size reduction method applies only to chemical processes. An example of cellulose nanostructures obtained by catalytic solvolysis carried out in the mixture with acetic acid and octanol-1 (Torlopov et al., 2015) is presented in a paper of Krivoshapkina et al. (2019). Cellulose nanoparticles were $20 \mathrm{~nm}$ diameter and $220 \mathrm{~nm}$ length. The idea of this froth flotation conducted with these nanostructures was to separate titanium in its oxidised forms (rutile and anatase) from silica. Flotation was successful in the $\mathrm{pH}$ range 2-3 due to the formation of oppositely charged structures consisting of titanium oxide with adsorbed nanocellulose. It was also observed that cellulose nanostructures did not interact with silica particles.

Nanocelluloses may also be applied in flocculation processes. The ability to aggregate particles into larger units is particularly useful for the separation of fine particles. This feature can be useful in wastewater treatment as well as in the recovery of low-grade ores, mostly when the particles must be finely ground to liberate valuable components (Kemppainen et al., 2016). In this case, nano-fibrillated cellulose was functionalised using sodium metabisulfite, giving anionic sulfonated cellulose and anionic dicarboxylic acid cellulose obtained by chlorite oxidation. In a mixture of fine particles of quartz and hematite, the hematite was capable of selective flocculation.

\subsection{Inorganic nanoparticles as flotation enhancers}

Foam stability is an important aspect of the final stage of the flotation process. Flotation aggregates accumulate on top of the flotation tank and then are removed. After dewatering the froth, the process is completed, and the concentrate is obtained. The presence of nanoparticles reduces foam formation but increases foam stability. It enables a reduction of the consumption of frothers in the flotation solution when the surfaces of nanostructures are ionic in nature (Arriaga et al., 2012). This phenomenon has been explained both by studies on the kinetics of liquid film drainage (Legawiec and Polowczyk, 2020), and electrostatic interactions at interphase boundaries (Liu et al., 2013). In general, nanoparticles retard foam ageing processes such as coalescence. Foam stability improvement can be seen in Fig. 4A. After introducing $0.01 \% \mathrm{w} / \mathrm{w}$ of silica nanoparticles (SNPs) in a system with anionic (sodium dodecylsulfate) or cationic (cetyltrimethylammonium bromide) surfactant the foam degradation was slowed compared to the system consisting of a surfactant only. The measurements of transmittance change with sample height in time (Fig. 4B) give exact results, helpful in determining the foam drainage kinetics.

Inorganic nanoparticles are usually not used as collectors because they have a weak interaction with the surface of the mineral (Hajati et al., 2016; Hajati et al., 2018) and consequently do not provide a sufficient mineral particle hydrophobicity. The adsorption of inorganic nanoparticles (raw silicon dioxide and both modified by sulfonation and PEG-ylation) was investigated in the systems of quartz and calcite (Metin et al., 2012). The authors concluded that in this case, adsorption of SNPs is insignificant.

Nasirimoghaddam et al. (2019) found that $\mathrm{Al}_{2} \mathrm{O}_{3}, \mathrm{Fe}_{2} \mathrm{O}_{3}, \mathrm{SiO}_{2}$ and $\mathrm{TiO}_{2}$ can promote column flotation of copper ore as froth stabilisers. By using $\mathrm{Al}_{2} \mathrm{O}_{3}$ nanoparticles (20 nm diameter), with a dosage of 6 $\mathrm{mgg}^{-1}$, it is possible to achieve the best both recovery and grade. The recovery of precious metals by flotation is another example of successful inorganic nanoparticles application. Mallampati et al. (2018) used flotation for the recovery of metals such as $\mathrm{Ag}, \mathrm{Au}, \mathrm{Pt}, \mathrm{Pd}, \mathrm{Rh}, \mathrm{Ru}, \mathrm{Ir}, \mathrm{Cu}$ and $\mathrm{Al}$ from milled scrapped end-of-life vehicles. The separation process was realised in the presence of nano-Fe/ $\mathrm{Ca} / \mathrm{CaO}$ mixture and MIBIC as a collector. In such a system, an exciting mechanism was identified. Precious metal cations were bound selectively by the cementation process (see also Mallampati et al., 2016). Cement-like shells gave a sufficient hydrophobicity and improved bubble attachment. Furthermore, as a result, in this application, the presence of inorganic nanoparticles enhanced foam stability. According to the authors, the process is economically beneficial and environmentally friendly. 
A

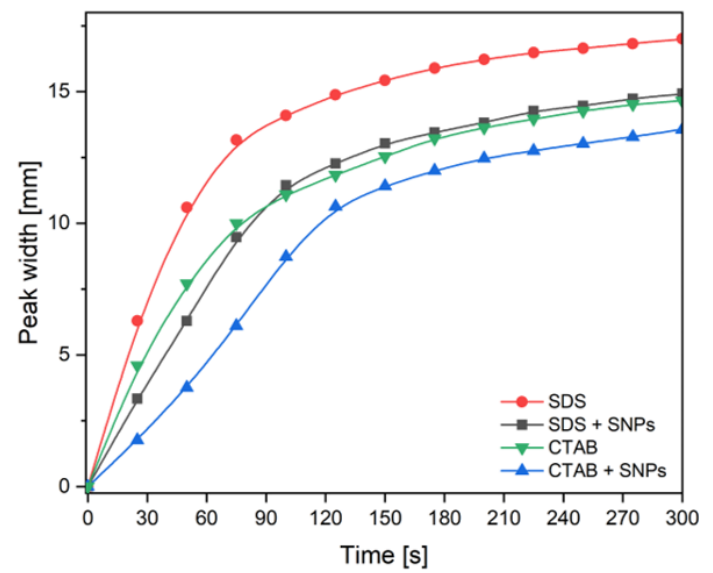

B

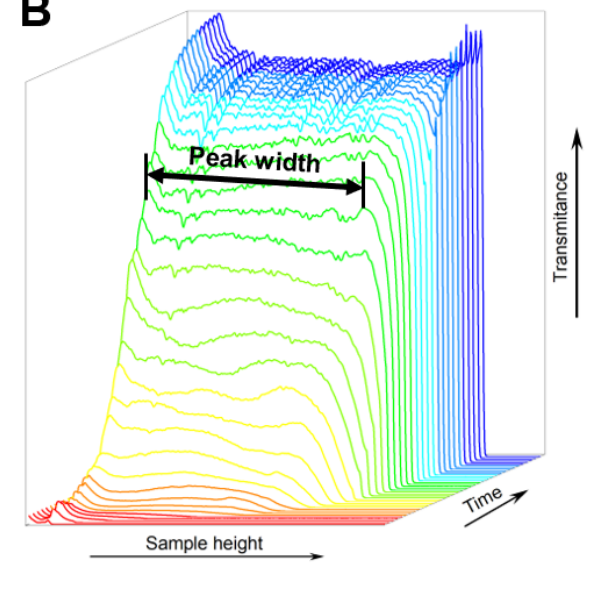

Fig. 4. A - the kinetics of foam drainage measured by turbidimetric apparatus Turbiscan Lab Expert (Formulaction). B - changes in transmittance and sample height in time. The foam was generated in the ionic surfactant solutions in the presence or absence of silica nanoparticles (SNPs)

\section{Conclusions and future perspectives}

This review summarises and organises information about attempts to use nanoparticles as flotation enhancers. The main conclusions are as follows:

- It is possible to produce polystyrene nanoparticles with modified surface chemistry to obtain an effective flotation collector, not only for model systems but also for metal ores. The real problem to be confronted is the long-term research to find functional groups that can be attached to the polystyrene core and which would give the nanostructures the properties characteristic for a flotation collector. Another aspect is the impact of polystyrene on the environment and human beings. For most synthetic organic nanostructures, the greatest danger is that they can accumulate not only in surface and underground waters but also in living organisms.

- Functionalised cellulose nanostructures can possess a tuneable hydrophobicity and adsorb at the interphase boundaries. In the case of the functionalisation of cellulose by amine derivatives, it is possible to obtain a reproducible hydrophobicity; therefore, it will be possible to precisely describe the behaviour of these structures at the interphase depending on the parameters of the functional groups attached.

- Inorganic nanoparticles can also be used as flotation enhancers. The most significant benefit of their use is to increase froth stability. It can contribute to a reduction of frother reagents consumption, and it is another opportunity to control froth stability during the flotation process.

- The main problem of replacing conventional molecular collectors with nanostructures is the economics aspect. Research published so far shows that the dosage must be higher for nanostructures than for conventional collectors.

- The most promising property of collectors based on nanostructures is their relatively simple functionalisation. By attaching various functional groups, it is possible to improve the selectivity of the flotation process. This suggests it is necessary to continue research in order to find more convenient and more effective methods of nano-collector functionalisation. Strategies already known, such as high throughput screening, will be helpful for this purpose. Additionally, one of the most exciting directions of research can be to try to reduce the levels of applied concentrations of e.g. xanthogenates by using adequate mixtures containing nano-collectors and conventional flotation reagents.

\section{Acknowledgements}

This article was financed in part by a statutory activity subsidy from the Polish Ministry of Science and Higher Education for the Department of Process Engineering and Technology of Polymer and Carbon Materials of the Wroclaw University of Science and Technology. 


\section{References}

ABARCA, C., ALI, M.M., PELTON, R.H., 2018. Choosing mineral flotation collectors from large nanoparticles libraries. J. Colloid Interface Sci. 516, 423-430.

ABARCA, C., YANG, S., PELTON, R.H., 2015. Towards high throughput screening of nanoparticle flotation collectors. J. Colloid Interface Sci. 460, 97-104.

ACKERMAN, P.K, HARRIS, G.H., KLIMPEL, R.R., APLAN, F.F., 1987. Evaluation of flotation collectors for copper sulfides and pyrite, III. Effect of xanthate chain length and branching. Int. J. Miner. Process. 21(1-2), 141-156.

ACKERMAN, P.K., HARRIS, G.H., KLIMPEL, R.R., APLAN, F.F., 1999. Use of chelating agents as collectors in the flotation of copper sulfides and pyrite. Trans. Soc. Min. Metall. Explor. 16, 27-35.

AN, M., LIAO, Y., CAO, Y., ZHAO, Y., QIU, Y., 2019. Tetrahydrofurfuryl-functionalized polystyrene nanoparticles as collectors for low rank coal floatation. Physicochem. Probl. Miner. Process. 55(2), 516-527.

AN, M., LIAO, Y., GUI, X., ZHAO, Y., HE, Y., LIU, Z., LAI, Q., 2017. An investigation of coal flotation using nanoparticles as a collector. Int. J. Coal Prep. Util., 1-11.

ARAUJO, D. M., YOSHIDA, M. I., TAKAHASHI, J. A., CARVALHO, C. F., STAPELFELDT, F., 2010. Biodegradation studies on fatty amines used for reverse flotation of iron ore. Int. Biodeterior. 64(2), 151-155.

CHEN, S., GONG, W., MEI, G., ZHOU, Q., BAI, C., XU, N., 2011. Primary biodegradation of sulfide mineral flotation collectors. Miner. Eng. 24(8), 953-955.

DHAR, P., THORNHILL, M., KOTA, R.H., 2019. Investigation of Copper Recovery from a New Copper Ore Deposit (Nussir) in Northern Norway: Dithiophosphates and Xanthate-Dithiophosphate Blend as Collectors. Minerals 9(146).

DONG, X., PRICE, M., DAI, Z., XU, M., PELTON, R., 2017. Mineral-mineral particle collisions during flotation remove adsorbed nanoparticle flotation collectors. J. Colloid Interface Sci. 504, 178-185.

FLETCHER, P.D.I., HOLT, B., 2011. Controlled Silanization of Silica Nanoparticles to Stabilise Foams, Climbing Films, and Liquid Marbles. Langmuir 27, 12869-12876.

FUERSTENAU, M., JAMESON, G., YOON, R., 2007. Froth flotation: a Century of Innovation. Soc. For Mining, Mineralurgy and Exploration. Littleon, Collorado.

GOODWIN, J.W., OTTEWILL, R.H., PELTON, R., 1979. Studies on the preparation and characterisation of monodisperse polystyrene lattices. 5. Preparation of cationic lattices. Colloid Polym. Sci. 257, 61-69.

HAJATI, A., SHAFAEI, S.Z., NOAPARAST, M., FARROKHPAY, S., ASLANI, S., 2016. Novel application of talc nanoparticles as collector in flotation. RCS Adv. 6, 98096-98103.

HAJATI, A., SHAFAEI, Z., NOAPARAST, M., FARROKHPAY, S., ASLANI, S., 2018. Investigating the effects of the particle size and dosage of talc nanoparticles as a novel solid collector in quartz flotation. Int. J. Min. Geo-Eng 53(1), 16.

HARTMANN, R., KINNUEN, P., ILLIKAINEN, M., 2018. Cellulose-mineral interactions based on the DLVO theory and their correlation with flotability. Miner. Eng. 122, 44-52.

HARTMANN, R., RUDOLPH, M., ÄMMÄLÄ, A., ILLIKAINEN, M., 2017. The action of cellulose-based and conventional flotation reagents under dry and wet conditions correlating inverse gas chromatography to microflotation studies. Miner. Eng. 114, 17-25.

HARTMANN, R., SIRVIÖ, J.A., SLIZ, R., LAITINEN, O., LIIMATAINEN, H., ÄMMÄL̈̈, A., FABRITIUS, T., ILLIKAINEN, M., 2016. Interactions between aminated cellulose nanocrystals and quartz: Adsorption and wettability studies. Colloids Surf. A 489, 207-215.

ISLAM, M.T., ALAM, M.M., PARTRUCCO, A., MONTRASOLO, A., ZOCCOLA, M., 2014. Preparation of Nanocellulose: A Review. AATCC J. Res. 1(5), 17-23.

KEMPPAINEN, K., SUOPAJÄRVI, T., LAITINEN, O., ÄMMÄLÄ, A., LIIMATAINEN, H., 2016. Flocculation of fine hematite and quartz suspensions with anionic cellulose nanofibers. Chem. Eng. Sci. 148, 256-266.

KOSIOR, D., KOWALCZUK, P.B., ZAWALA, J., 2018. Surface roughness in bubble attachment and flotation of highly hydrophobic solids in presence of frother - experiment and simulations. Physicochem. Probl. Miner. Process. 54(1), 6372.

KRIVOSHAPKINA, E.F., MIKHAYLOV, V.I., PEROVSKIY, I.A., TORLOPOV, M.A., RYABKOV, Y.I., KRIVOSHAPKIN, P.V., 2019. The effect of cellulose nanocrystals and $p H$ value on the flotation process for extraction of minerals. J. Solgel. Sci. Technol. 92, 319-326.

KYZAS, G.Z., MATIS, K.A., 2019. The flotation process can go green. Processes 7(138). 
LAITINEN, O., HARTMANN, R., SIRVIÖ, J.A., LIIMATAINEN, H., RUDOLPH., M., ÄMMÄLÄ, A., ILLIKAINEN., M., 2016. Alkyl aminated nanocelluloses in selective flotation of aluminium oxide and quartz. Chem. Eng. Sci. 144, 260266.

LAITINEN, O., KEMPPAINEN, K., ÄMMÄLÄ, A., SIRVIÖ, J.A., LIIMATAINEN, H., NIINIMÄKI, J., 2014. Use of Chemically Modified Nanocelluloses in Flotation of Hematite and Quartz. Ind. Eng. Chem. Res. 53, 20092-20098.

LEGAWIEC, K.J., POLOWCZYK, I., 2020. Synergic Nanoparticles-Cationic Surfactant Interactions for Controlling Foam Systems. Practical Aspects of Chemical Engineering. PAIC 2019. Springer, Cham.

LIIMATAINEN, H., SIRVIÖ, J.A., SUNDMAN, O., HORMI, O., NIINIMÄKI, J., 2012. Use of nanoparticular and soluble anionic celluloses in coagulation-flocculation treatment of kaolin suspension. Water Res. 46, 2159-2166.

LIIMATAINEN, H., VISANKO, M., SIRVIÖ, J.A., HORMI, O., NIINIMÄKI, J., 2012, Enhancement of the nanofibrillation of wood cellulose through sequential periodate-chlorite oxidation. Biomacromolecules 13, 1592.

LOPÉZ, R., JORDÃO, H., HARTMANN, R., ÄMMÄLÄ, A., CARVALHO, M.T., 2019. Study of butyl-amine nanocrystal cellulose in the flotation of complex sulphide ores. Colloids Surf. A 579, 123655.

MALLAMPATI, S.R., LEE, B.H., MITOMA, Y., SIMON, C., 2018. Sustainable recovery of precious metals from end-oflife vehicles shredder residue by a novel hybrid ball-milling and nanoparticles enabled froth flotation process. J. Clean. Prod. 171, 66-75.

MALLAMPATI, S.R., HEO, J.H., PARK, M.H., 2016. Hybrid selective surface hydrophilisation and froth flotation separation of hazardous chlorinated plastics from E-waste with novel nanoscale metallic calcium composite. J. Hazard. Mater. 306, 13-23.

NAGARAJ, D.R., FARINATO, R.S., 2016. Evolution of flotation chemistry and chemicals: A century of innovations and the lingering challenges. Miner. Eng. 96-97, 2-14.

NASIRIMOGHADDAM, S., MOHEBBI, A., KARIMI, M., YARAHMADI, M.R., 2020. Assessment of pH-responsive nanoparticles performance on laboratory column flotation cell applying a real ore feed. Int. J. Min. Sci. Technol. 30(2), 197-205.

SAJJADI, S., 2006. Nanoparticle formation by monomer-starved semi-batch emulsion polymerisation. Langmuir 23, 10181024.

SIRVIÖ, J., HYVAKKO, U., LIIMATAINEN, H., NIINIMAKI, J., HORMI, O., 2011. Periodate oxidation of cellulose at elevated temperatures using metal salts as cellulose activators. Carbohydr. Polym. 83, 1293-1297.

SPERLING, R.A, PARAK, W.J., 2010. Surface modification, functionalisation and bioconjugation of colloidal inorganic nanoparticles. Phil. Trans. R. Soc. A. 368, 1333-1383.

SUOPÄJARVI, T., LIIMATAINEN, H., KARJALAINEN, M., UPOLA, H., NIINIMÄKI, J., 2015. Lead adsorption with sulfonated wheat pulp nanocelluloses. J. Water Process Eng. 5, 136-142.

TORLOPOV, M.A., MIKHAYLOV, V.I., UDORATINA, E.V., ALESHINA, L.A., PRUSSKII, A.I., NIKOLAY V. TSVETKOV, KRIVOSHAPKIN, P.V., 2019. Cellulose nanocrystals with different length-to-diameter ratios extracted from various plants using novel system acetic acid/phosphotungstic acid/octanol-1. Cellulose 25, 1031-1046.

VALLE-DELGADO, J.J., MOLINA-BOLIVAR, J., GALISTEO-GONZALEZ, F., GALVEZ-RUIZ, M.J., 2003. Study of the colloidal stability of an amphoteric latex. Colloid Polym. Sci. 281(8), 708-715.

YANG, S., PELTON, R., 2011. Nanoparticle Flotation Collectors II: The Role of Nanoparticle Hydrophobicity. Langmuir 27, 11409-11415.

YANG, S., PELTON, R., ABARCA, C., DAI, Z., MONTGOMERY, M., XU, M., BOS, J.A., 2013. Towards nanoparticle flotation collectors for pentlandite separation. Int. J. Miner. Process. 123, 137-144.

YANG, S., PELTON, R., MONTGOMERY, M., CUI, Y., 2012. Nanoparticle Flotation Collectors III: The role of Nanoparticle Diameter. ASC Appl. Mater. Interfaces 4, 4882-4890.

YANG, S., PELTON, R., RAEGEN, A., MONTGOMERY, M., DALNOKI-VERESS, K., 2011. Nanoparticle Flotation Collectors: Mechanism Behind a New Technology. Langmuir 27, 10438-10446.

YOSHIMURA, K., MACHIDA, S., \& MASUDA, F., 1980. Biodegradation of long chain alkylamines. J. Am. Oil Chem. Soc. $57(7), 238-241$. 